\title{
Comparison of functional performance and physical activity levels between individuals with and without leprosy
}

\author{
Comparação do desempenho funcional e níveis de atividade física entre \\ indivíduos com e sem hanseníase
}

Indira dos Santos Silva ${ }^{1}$

Bruno Remígio Cavalcante ${ }^{2}$

José Fernando Vila Nova de Moraes ${ }^{3}$

Mariana Ferreira de Souza ${ }^{4}$

\section{Correspondence}

Mariana Ferreira de Souza, $\mathrm{PhD}$

Clinical Exercise Lab - LABEC; Department of

Physical Education at Federal University of Vale do São Francisco (CEFIS-UNIVASF); José de Sá Maniçoba Ave, S/N - Centro, Petrolina - PE, ZipCode: 56304-917; E-mail:

mariana.ferreirasouza@univasf.edu.br

Department of Physical Education, Federal University of Vale do São Francisco (UNIVASF), Petrolina,

Pernambuco, Brazil

indira.santos.silva@gmail.com

2 (iD) Associated Graduate Program in Physical Education UPE-UFPB, University of Pernambuco, Recife,

Pernambuco, Brazil

br_13remigio@hotmail.com

3 (iD) Department of Physical Education, Federal University of Vale do São Francisco (UNIVASF), Petrolina,

Pernambuco, Brazil. Graduated Program in Physical

Education, Federal University of Vale do São Francisco,

Petrolina, Pernambuco, Brazil.

josefernando.moraes@univasf.edu.br

4 (iD) Department of Physical Education, Federal University

of Vale do São Francisco (UNIVASF), Petrolina,

Pernambuco, Brazil. Graduated Program in Physical

Education, Federal University of Vale do São Francisco,

Petrolina, Pernambuco, Brazil.

mariana.ferreirasouza@univasf.edu.br

\begin{abstract}
Introduction: Individuals with leprosy have poor musculoskeletal function and quality of life. However, whether the disease influences functional performance and physical activity is poorly understood.

Aim: To compare the functional performance and physical activity levels between individuals with and without leprosy.

Methods: This cross-sectional study was composed of 60 individuals (30 with leprosy and 30 healthy age-matched controls) of both sexes. The degree of disability was assessed according the World Health Organization recommendations. A functional performance core battery and moderate-to-vigorous physical activity was obtained.

Results: Compared with control, individuals with leprosy presented poor functional performance. No between-group differences were observed for handgrip strength or moderate-to-vigorous physical activity $(\mathrm{p}>0.05)$. Additionally, the functional impairment was higher among leprosy individuals with disability $(\mathrm{p}<0.01)$.

Conclusion: Individuals with leprosy present functional impairment when compared to age-matched healthy controls, and this impairment is amplified as the disease worsens
\end{abstract}

Keywords: Leprosy. Physical functional performance. Motor activity.

\section{Resumo}

Introdução: indivíduos com hanseníase apresentam pior função musculoesquelética e qualidade de vida. No entanto, o quanto a doença influencia o desempenho funcional e a atividade física é pouco compreendido.

Objetivo: Comparar o desempenho funcional e níveis de atividade física entre indivíduos com e sem hanseníase.

Métodos: Este estudo transversal foi composto de 60 indivíduos (30 com hanseníase e 30 indivíduos saudáveis) de ambos os sexos. O grau de incapacidade foi avaliado de acordo com as recomendações da Organização Mundial de Saúde. Uma bateria de testes funcionais e a atividade física moderada a vigorosa foram obtidos.

Resultados: Comparado com o grupo controle, indivíduos com hanseníase apresentaram menor desempenho funcional. Não foram observadas diferenças significantes para a força de preensão manual e atividade física moderada a vigorosa ( $>$ > 0.05). Adicionalmente, o prejuízo funcional foi maior entre indivíduos com grau de incapacidade $(\mathrm{p}<0.01)$.

Conclusão: Indivíduos com hanseníase apresentam pior desempenho funcional, e esse comprometimento é amplificado com a piora da doença.

Descritores: Hanseníase. Desempenho físico funcional. Atividade motora.

Cite it like this:

Silva IS, Cavalcante BR, Moraes JFVN, Souza MF.

Comparison of functional performance and physical activity levels between individuals with and without leprosy

Conscientiae Saúde 2019 July/Sept.; 18(3):366-375. https://doi.org/10.5585/ConsSaude.v18n3 13859. 


\section{Introduction}

Leprosy is a chronic infectious contagious disease that is caused by mycobacterium leprae, a bacillus with affinity for cutaneous cells and peripheral nerves (sensory, motor, and/or autonomic) which has the respiratory tract as the main route of contamination ${ }^{1,2}$. As a consequence, diagnosed individuals present skin lesions with altered sensitivity and peripheral nerve thickening, as well as positive smear microscopy for Hansen's bacillus ${ }^{1,3}$.

Although the incidence of leprosy declined from 2006 to 2015, the disease control is still poor ${ }^{4}$. In Brazil, its prevalence is high, we have the second highest incidence of leprosy in the world, losing only to India. The largest case detection is in the Brazilian northeast, where the states presented a prevalence coefficient above the national average ${ }^{5}$. Particularly in Petrolina, a city located in PE state and border with BA, according to the Municipal Health Department, about 70 new cases of the disease per 100,000 inhabitants were diagnosed in 2018, making it a hyperendemic region.

Multidrug therapy is a first-line and effective treatment for individuals with leprosy ${ }^{1}$. However, when undiagnosed and inadequately treated, the patient's clinical condition can be aggravated, resulting in neuromotor impairments. In the peripheral nervous system, Schwann cells have basal lamina receptors that recognize mycobacterium leprae antigen, which allows the binding or invasion of these cells, which can lead to neural damage ${ }^{6}$. As a result, patients may develop deficiencies and physical deformities, functional disabilities, responsible for the high morbidity of leprosy, which may reduce the walking performance, muscle strength, physical activity levels and quality of life of these patients ${ }^{7-9}$.

Physical activity is related to maintenance or improvement of mobility and functional capacity in patients with different comorbidities ${ }^{10}$. Nonetheless, the extent to which these disease-associated impairments caused by leprosy affect functional performance and physical activity levels is poorly understood ${ }^{8,11}$. Apparently, both the presence and degree of severity of the disease, caused by the injury of the peripheral nerves, negatively influence the functional capacity, especially the walking capacity and palmar grip strength in these patients ${ }^{9}$. On the other hand, the results observed in relation to physical activity levels are still controversial ${ }^{7,8,11}$.

In this line, understanding the changes in these outcomes when compared to healthy controls could provide information to help design more appropriate physical activity and functional rehabilitation programs for this sub-group. Therefore, the aim of our study was to compare the functional performance and physical activity levels between individuals with and 
without leprosy in Petrolina-PE. We also analyzed how these outcomes differ by degree of disability according to the World Health Organization (WHO) ${ }^{12}$.

\section{Methods}

\section{Participants}

This cross-sectional study was composed of 60 participants (30 individuals with leprosy and 30 age-matched healthy controls), of both sexes. All individuals were recruited in the Primary Care Network of the city of Petrolina (which includes the Basic Health Units associated with the Local Health Secretary). The inclusion criteria were: aged 18 years or older, literate, physically independent, no previous neurological and/or psychiatric diseases, and no cardiac and/or musculoskeletal disorders that limited participation in the functional tests. All participants with leprosy were under the use of multidrug therapy. Individuals who did not perform the functional tests or did not respond adequately to the physical activity questionnaire were excluded.

The study was approved by the local ethics committee (Protocol CAAE number 67013617.4.0000.5196) and informed consent was obtained from all participants prior to the measurements.

\section{Measures}

\section{Screening of participants}

The demographic (age, sex, and education), medical, and medication use history were obtained through face-to-face interview. The anthropometric information on body mass and stature were obtained using a digital scale and stadiometer, respectively. The quotient of body mass by stature squared was used to calculate the body mass index.

\section{Degree of disability}

The neurological assessment and measurement of the degree of disability of the patients with leprosy were performed by an experienced nurse using the national simplified neurological 
assessment protocol and classification of the degree of disability proposed by the $\mathrm{WHO}^{12}$, respectively, where individual scores are assigned based on several hand, eye, and foot assessments. Briefly, the patient's physical disability was classified as: i) grade 0: refers to the absence of physical disability; ii) grade 1: refers to the presence of disability; iii) grade 2: refers to the presence of disability and complications ${ }^{12}$.

\section{Functional and physical activity assessment}

Functional performance and grip strength were evaluated by the six-minute walk test $(6 \mathrm{MWT})^{13}$, short physical performance battery (SPPB $)^{14}$, timed up and go (TUG) $)^{15}$, and 4-meter gait speed test ${ }^{16}$. All these tests are widely used and validated for functional capacity assessment.

Briefly, the 6MWT consists of walking along a 30-meter corridor during which the participants are encouraged to walk for six-minutes and cover as much ground as possible. At the end of six minutes, the total distance walked (defined as the maximum distance completed at the end of the six minutes in meters) were recorded ${ }^{13}$. Additionally, the TUG measures the time (in seconds) the participant needs to get up from a chair, walk 3 meters towards a line, circle around it (180 degrees), return, and sit back on the chair (a shorter time to complete the TUG indicates better performance) $)^{15}$.

The SPPB is composed of five tests that allow evaluation of the balance, gait, and strength/endurance of lower limbs. The standing balance included side-by-side, tandem, semitandem stands. The participant must be positioned in each stand for 10 seconds. The participant's usual gait speed over $4 \mathrm{~m}$ was recorded using a stopwatch and the faster of the two attempts was used. To assess the strength/endurance of lower limbs, the ability to sit-to-stand five-times from a chair was used. A straight-backed chair was placed next to a wall, participants were asked to fold their arms across their chest and to stand up and sit down five times as quickly as possible, and the time (in seconds) were recorded. Each test has a specific score based on the participant's performance. The total score was obtained by the sum of the scores of each test, ranging from 0 to 12 (the maximum score indicates better performance) ${ }^{14}$.

The maximum voluntary isometric contraction was obtained using a hand-held adjustable hydraulic dynamometer and calibrated with a scale of zero to $100 \mathrm{~kg}$, following previously described procedures and recommendations ${ }^{17}$. Prior to testing, participants received the necessary guidance and handled the equipment by performing some contractions to familiarize 
themselves with the equipment. In addition, the hand positioning was adjusted so that the proximal interphalangeal joint of the hand was adjusted under the bar to allow the grip to be held between the fingers and the tensile region with maximum comfort. After five minutes of rest, the maximum voluntary isometric contraction in both hands were obtained after three attempts with a recovery interval of one minute between each. During the test, it was recommended that the arm remain immobile, with only flexion of the interphalangeal joints and phalangeal metacarpal, in addition verbal incentives were performed.

The time spent in moderate-to-vigorous physical activity were measured through the short version of the International Physical Activity Questionnaire (IPAQ) ${ }^{18}$. The questionnaire was applied as a face-to-face interview. IPAQ quantifies physical activity during the last seven days divided into four categories: vigorous intensity, moderate intensity, walking and sitting. In addition to intensity, frequency and duration of physical activity are also assessed. Responses were scored according to the IPAQ-protocol after summation of the duration (in minutes) and frequency (in days) of the different physical activity intensities.

\section{Statistical analysis}

Normality was checked using the Shapiro Wilk test. Differences between groups (leprosy vs. age-matched healthy controls; individuals with vs. without disability) were analyzed with an independent t-test. The effect size (ES) was calculated to verify the magnitude of the differences by Cohen's $\mathrm{d}^{19}$. In this study, we did not perform a prior sample size calculation, however, the computed achieved power was $0.05,0.05,0.31,0.98,0.82,0.99$ and 0.89 for MVPA, handgrip right/left hand, SPBB, TUG, 6MWT and gait speed, respectively. Data were analyzed using the Statistical Package for the Social Sciences (SPSS Version 22.0 for Windows).

\section{Results}

Table 1 shows the main characteristics of the study participants. There was similarity in age, body mass, and stature between groups, however, individuals with leprosy presented higher body mass index values. 
Table 1 - Main characteristics of the participants

\begin{tabular}{lllll}
\hline & $\begin{array}{l}\text { Leprosy } \\
(\mathbf{n}=30)\end{array}$ & $\begin{array}{l}\text { Healthy } \\
(\mathbf{n}=30)\end{array}$ & CI 95\% & $P$ \\
\hline Age $(\mathrm{yrs})$ & $48(14)$ & $44(17)$ & $-12 ; 4$ & 0.27 \\
Body mass $(\mathrm{kg})$ & $67.8(13.1)$ & $74.1(11.4)$ & $-0.9 ; 12.6$ & 0.06 \\
Stature $(\mathrm{cm})$ & $164.5(8.1)$ & $165.4(6.9)$ & $-3.1 ; 4.7$ & 0.67 \\
Body mass index $\left(\mathrm{kg} / \mathrm{m}^{2}\right)$ & $24.9(4.1)$ & $27.1(3.0)$ & $0.3 ; 4.1$ & 0.02 \\
\hline
\end{tabular}

Fonte: Autores.

Table 2 presents the comparisons of functional performance and physical activity measures between groups. The leprosy group demonstrated lower values in the SPPB, TUG, 6MWT, and gait speed when compared to the control group. The effect sizes varied from moderate to large (0.76-1.19). On the other hand, no significant differences were observed for handgrip strength or MVPA ( $\mathrm{p}>0.05)$.

Table 2 - Comparison of functional performance and physical activity levels between individuals with and without leprosy

\begin{tabular}{clllll}
\hline & $\begin{array}{l}\text { Leprosy } \\
(\mathbf{n}=30)\end{array}$ & $\begin{array}{l}\text { Healthy } \\
(\mathbf{n}=30)\end{array}$ & CI 95\% & P & ES \\
\hline MVPA (min) & $334.17(354.15)$ & $315.67(329.10)$ & $-195.18 ; 158.18$ & 0.83 & 0.05 \\
Handgrip (kgf) & & & & & \\
Right & $33.63(11.48)$ & $34.47(10.20)$ & $-4.78 ; 6.44$ & 0.76 & 0.07 \\
Left & $26.93(14.95)$ & $31.87(9.81)$ & $-1.60 ; 11.46$ & 0.13 & 0.39 \\
SPPB (score) & $9.70(2.53)$ & $11.70(0.65)$ & $1.02 ; 2.97$ & $<0.01$ & 1.08 \\
TUG (sec) & $10.91(5.69)$ & $7.71(1.86)$ & $-5.42 ;-0.47$ & $<0.01$ & 0.76 \\
6MWT (meters) & $382.12(134.66)$ & $550.78(146.79)$ & $95.86 ; 241.46$ & $<0.01$ & 1.19 \\
Gait speed (m/s) & $0.91(0.21)$ & $1.06(0.14)$ & $0.05 ; 0.24$ & $<0.01$ & 0.84 \\
\hline
\end{tabular}

Note: SPPB-Short Physical Performance Battery; MVPA- Moderate-to-vigorous physical activity; TUG-timed up and go; 6MWT-Six-minute walk test; ES- Effect size.

Of the total of 30 individuals with leprosy, $23 \%(n=7)$ presented a degree of disability of 1 , and $10 \%(n=3)$ were classified as grade 2 . In order to compare the degrees of disability, according to the WHO, the leprosy group was divided into two groups: with vs. without disability (Table 3). The disability group presented lower values for SPPB, handgrip strength (left hand), 6MWT, and gait speed when compared to the group without disability (p <0.01), and the magnitudes of effect sizes were large (1.01-1.55). No significant differences between groups were observed for handgrip strength (right hand), TUG, or MVPA ( $>$ > 0.05). 
Table 3 - Comparison of functional performance and physical activity levels between degrees of disability according to the WHO in individuals with leprosy

\begin{tabular}{clllll}
\hline & $\begin{array}{l}\text { Degree "0" } \\
(\mathbf{n = 2 0})\end{array}$ & $\begin{array}{l}\text { Degree "1-2" } \\
(\mathbf{n = 1 0})\end{array}$ & CI 95\% & P & ES \\
\hline MVPA (min) & $399.00(389.22)$ & $204.50(237.28)$ & $-81.34 ; 470.37$ & 0.16 & 0.60 \\
Handgrip (kgf) & & & & & \\
$\quad$ Right & $35.25(11.46)$ & $30.40(11.41)$ & $-4.23 ; 13.93$ & 0.28 & 0.42 \\
$\quad$ Left & $33.20(10.99)$ & $14.40(14.26)$ & $9.16 ; 28.43$ & $<0.01$ & 1.39 \\
SPPB (score) & $10.80(1.50)$ & $7.50(2.79)$ & $1.23 ; 5.37$ & $<0.01$ & 1.47 \\
TUG (sec) & $9.40(2.47)$ & $13.93(8.74)$ & $-10.84 ; 1.77$ & 0.14 & 0.70 \\
6MWT (meters) & $426.15(101.45)$ & $294.04(154.19)$ & $36.16 ; 228.06$ & $<0.01$ & 1.01 \\
Gait speed (m/s) & $0.99(0.17)$ & $0.72(0.18)$ & $0.11 ; 0.41$ & $<0.01$ & 1.55 \\
\hline
\end{tabular}

Note: SPPB- Short Physical Performance Battery; MVPA- Moderate-to-vigorous physical activity; TUG- timed up and go; 6MWT- Six-minute walk test; ES- Effect size.

\section{Discussion}

This cross-sectional study showed that individuals with leprosy presented marked functional impairment when compared to healthy people and that this functional impairment is amplified as the disease worsens. In contrast, physical activity levels were similar between individuals with and without the disease.

Leprosy affects the peripheral nerves and, if not properly diagnosed and treated, may worsen the patient's clinical condition, causing neuromotor damage, such as physical and functional impairments ${ }^{1}$. Herein, we confirmed that individuals diagnosed with leprosy demonstrated marked functional impairment and the presence of disability exacerbated these limitations. In fact, a previous study ${ }^{9}$ showed that leprosy patients with disability (grade 1-2) presented poor performance during the 6MWT when compared to patients without disability, and lower muscle strength during dorsiflexion, with low electromyographic activity of the anterior tibial when compared to healthy people ${ }^{8}$. This suggests that the progression of the disease may cause alterations in the areas enervated by peripheral nerves and, therefore, the action potentials generated for muscle contraction of the lower limbs may undergo negative changes that impact functional activity performance.

In addition, the literature highlights the importance of drug treatment for patients with leprosy. Even though the muscle mass and functional capacity of these patients is lower than their healthy peers, those who adhered to multidrug treatment presented better scores in these variables when compared to those who did not adhere to the use of medication ${ }^{20}$. However, all 
patients evaluated in the present study were undergoing drug treatment at the local Basic Health Units and yet, nevertheless, showed lower scores in functional performance tests.

Interestingly, our results demonstrate that the time spent in moderate to vigorous physical activity was similar between individuals with and without leprosy. Although there are a limited number of studies quantifying the physical activity levels of individuals with leprosy, Do Prado et al. ${ }^{11}$ observed no correlation between the degree of disability and physical activity levels in 97 patients with leprosy. On the other hand, Cheng et al. ${ }^{7}$ assessed the physical activity level and associated factors among 248 older adults (aged 75 yrs) institutionalized and diagnosed with leprosy (degree of disability 1). The results showed that the older adults with leprosy were less physically active when compared to the reference values of the older people without the disease. Although this study evaluated a large number of patients, the author did not compare the physical activity levels between individuals with leprosy and a healthy age-matched control group. In addition, both studies used questionnaires to measure physical activity. Thus, future studies should explore potential differences between individuals with and without leprosy and the degree of disability, using objective measurement techniques.

\section{Conclusion}

In summary, individuals with leprosy present functional impairment when compared with healthy controls, and this impairment is amplified as the disease worsens. No differences were observed in physical activity levels between participants. The clinical interpretation is that patients with leprosy who have poor functional performance may be prime candidates to improve this outcome through an exercise-targeted rehabilitation intervention.

\section{Acknowledgments}

The authors are grateful for the collaboration of the study participants.

\section{References}

1. Rodrigues LC, Lockwood DNJ. Leprosy now: Epidemiology, progress, challenges, and research gaps. Lancet Infect Dis. 2011;11(6):464-70.

2. The Lancet Neurology. Leprosy as a neurological disease. Lancet Neurol. 2009; 
3. Miko TL, Le Maitre C, Kinfu Y. Damage and regeneration of peripheral nerves in advanced treated leprosy. Lancet. 1993;

4. WHO. Global Leprosy Strategy 2016-2020: accelerating towards a leprosy-free world. Weekly Epidemiological record. 2016.

5. Ribeiro MD, Silva JC, Oliveira S. Estudo epidemiológico da hanseníase no Brasil: reflexão sobre as metas de eliminação. Rev Panam Salud Pública. 2018;

6. Virmond M. Leprosy rehabilitation - A shared responsibility. In: Indian Journal of Leprosy. 2003.

7. Cheng SP, Tang FI, Yu S, Chen IJ, Wu LL. Factors influencing physical activity in institutionalized elderly patients with leprosy. Rehabil Nurs. 2012;37(2):88-93.

8. Véras LST, Vale RGS, Mello DB, Castro JAF, Lima V, Silva KNG, et al. Degree of disability, pain levels, muscle strength, and electromyographic function in patients with Hansen's disease with common peroneal nerve damage. Rev Soc Bras Med Trop. 2012;45(3):375-9.

9. Slim FJ, Keukenkamp R, Van Schie CH, Faber WR, Nollet F. Foot impairments and limitations in walking activities in people affected by leprosy. J Rehabil Med. 2011;43(1):328 .

10. Pasanen T, Tolvanen S, Heinonen A, Kujala UM. Exercise therapy for functional capacity in chronic diseases: An overview of meta-analyses of randomised controlled trials. British Journal of Sports Medicine. 2017.

11. Prado GD, Prado RB, Marciano LH, Nardi SM, Cordeiro JA, Monteiro HL. WHO disability grade does not influence physical activity in Brazilian leprosy patients. Lepr Rev. 2011;82(3):270-8.

12. Brandsma JW, Van Brakel WH. WHO disability grading: operational definitions. Lepr Rev. 2003;74(4):366-73.

13. Crapo RO, Casaburi R, Coates AL, Enright PL, MacIntyre NR, McKay RT, et al. American Thoracic Society ATS Statement : Guidelines for the Six-Minute Walk Test. Am J Respir Crit Care Med. 2002;166(1):111-7.

14. Guralnik JM, Simonsick EM, Ferrucci L, Glynn RJ, Berkman LF, Blazer DG, et al. A short physical performance battery assessing lower extremity function: Association with selfreported disability and prediction of mortality and nursing home admission. Journals Gerontol - Ser A Biol Sci Med Sci. 1994;49(2):M85-94.

15. Barry E, Galvin R, Keogh C, Horgan F, Fahey T. Is the Timed Up and Go test a useful predictor of risk of falls in community dwelling older adults: A systematic review and metaanalysis. BMC Geriatr. 2014;14(14). 
16. Studenski S, Perera S, Wallace D, Chandler JM, Duncan PW, Rooney E, et al. Physical performance measures in the clinical setting. J Am Geriatr Soc. 2003;51(3):314-22.

17. Rantanen T, Harris T, Leveille SG, Visser M, Foley D, Masaki K, et al. Muscle strength and body mass index as long-term predictors of mortality in initially healthy men. J Gerontol A Biol Sci Med Sci. 2000;55(3):M168-73.

18. Hallal PC, Victora CG. Reliability and Validity of the International Physical Activity Questionnaire (Ipaq). Med Sci Sport Exerc. 2004;36(3):556.

19. Cohen J. Statistical power analysis for the behavioral sciences. Hillsdale, N.J.: L. Erlbaum Associates; 1988.

20. Lee SY, Kim W, Park HW, Park SC, Kim IK, Chung SG. Anti-sarcopenic effects of diamino-diphenyl sulfone observed in elderly female leprosy survivors: a cross-sectional study. J Cachexia Sarcopenia Muscle. 2016;7(3):322-9. 